\title{
Caracterização Microestrutural De Soldas Dissimilares Dos Aços Astm A-508 E AISI 316L
}

\author{
(Characterization of Dissimilar Metal Weld Between Low Alloy Steel ASTM A-508 and 316L Stainless Steel)
}

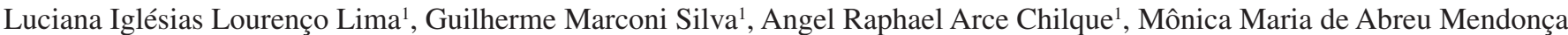 \\ Schvartzman², Alexandre Queiroz Bracarense'1, Marco Antônio Dutra Quinan² \\ ${ }^{1}$ Universidade Federal de Minas Gerais- Programa de Pós Graduação/Engenharia Mecânica \\ Belo Horizonte, Minas Gerais - lill@cdtn.br.gmarcsil@gmail.com, anarcec@yahoo.com,queiroz@demec.ufmg.br \\ ${ }^{2}$ Centro de Desenvolvimento da Tecnologia Nuclear, Serviço de Integridade Estrutural/Laboratório de Corrosão, Belo Horizonte, \\ Minas Gerais, Brasil_tronicas@cdtn.br, quinanm@cdtn.br
}

\begin{abstract}
Resumo
As soldas dissimilares (dissimilar metal welds - DMWs) são utilizadas em diversos segmentos da indústria. No caso específico de usinas nucleares, tais soldas são necessárias para conectar tubulações de aço inoxidável com componentes fabricados em aços baixa liga. Os materiais de adição mais utilizados neste tipo de solda são as ligas de níquel 82 e 182. Este trabalho consistiu na soldagem de uma junta dissimilar de aço baixa liga ASTM A-508 G3 e aço inoxidável austenítico AISI 316L utilizando as ligas de níquel 82 e 182 como metais de adição. A soldagem foi realizada manualmente empregando os processos de soldagem ao arco SMAW (Shielded Metal Arc Welding) e GTAW (Gas Tungsten Arc Welding). Os corpos de prova foram caracterizados microestruturalmente utilizando-se microscópio óptico e microscópio eletrônico de varredura com microanálise por dispersão de energia de raios X (EDS) e ensaios de microdureza Vickers. Observou-se uma microestrutura constituída de dendritas de austenita com a presença de precipitados com formas e dimensões definidas pelo aporte térmico e pela direção de soldagem. Não houve variação significativa da dureza ao longo da junta soldada, demonstrando a adequação dos parâmetros de soldagem utilizados.
\end{abstract}

Palavras-chave: Aço baixa liga. Aço inoxidável austenítico. Soldas dissimilares. Ligas de níquel. Caracterização microestrutural.

\begin{abstract}
The dissimilar metal welds (DMWs) are used in several areas of the industries. In the nuclear power plant, this weld using nickel alloy welding wires is used to connect stainless steel pipes to low alloy steel components on the reactor pressured vessels. The filler materials commonly used in this type of weld are nickel alloys 82 and 182.. In this study, dissimilar metal welds composed of low alloy steel ASTM A-508 G3, nickel alloys 82 e 182 as weld metals, and austenitic stainless steel AISI 316L were prepared by manual shielded metal arc welding (SMAW) and gas tungsten arc welding techniques (GTAW). Samples were microstructural characterized by optical microscopy and scanning electron microscopy using energy dispersive $\mathrm{X}$ ray microanalysis (EDS). It was noticed that there was a microstructure consisting of austenite dendrites with the presence of precipitates with shapes and dimensions set by the thermal contribution and direction of welding. There was no significant variation of hardness along the weld joint, demonstrating the suitability of the welding parameters used.
\end{abstract}

Key-words: Low alloy steel. Austenitic stainless steel. Dissimilar weld. Nickel alloys. Microstructural characterization.

\section{Introdução}

Soldas entre dois materiais diferentes, soldas dissimilares, são frequentemente utilizadas em diversos segmentos das indústrias química, petroquímica e nuclear. Em usinas nucleares estas soldas são empregadas para unir tubulações, em aço inoxidável austenítico, aos diversos vasos de pressão, construídos em aços

(Recebido em 23/12/2009; Texto final em 17/06/2010). baixa liga [1].

As usinas nucleares são centrais de geração de energia elétrica que utilizam a reação nuclear de fissão como fonte de calor para produção de energia. O reator do tipo PWR - Pressurized Water Reactor, reator refrigerado e moderado a água leve, foi a linha de reatores de potência adotada pelo Brasil na construção de suas centrais nucleares (Angra 1 e Angra 2). O princípio de funcionamento dessas usinas se baseia no resfriamento do núcleo do reator através de um circuito fechado de água à elevada pressão, denominado circuito primário. A água aquecida sob alta pressão no circuito primário passa por um trocador de calor (gerador de vapor) onde aquece e transforma em vapor a 
água do circuito secundário. Esse vapor movimenta uma turbina que aciona um gerador elétrico. A energia elétrica gerada chega aos consumidores finais através de redes de distribuição $[2,3]$.

Nas usinas nucleares do tipo PWR com tecnologia semelhante à utilizada na construção da usina de Angra 1, uma importante aplicação das soldas dissimilares é a união entre os vasos de pressão de aço carbono baixa liga (pressurizador, geradores de vapor e vaso de pressão do reator) e tubulações de aço inoxidável austenítico (Figura 1) [4,5].
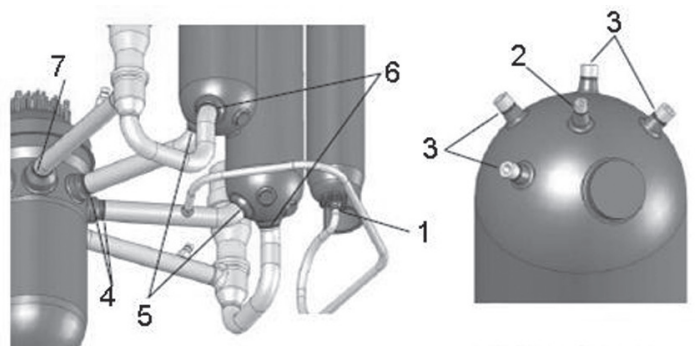

Gerador de vapor (GV) e Vaso do Reator

4 - Bocais de saída (Reator)

5 - Bocais de saída (GV)

6 - Bocais de entrada (GV)

7 - Bocal de entrada (Reator)

\section{Pressurizador:}

1 - Bocais da linha de pressão

2 - Bocal de pressurização
3 - Bocal válvula de alívio

Figura 1 - Desenho esquemático evidenciando algumas juntas soldadas dissimilares existentes no circuito primário de uma usina nuclear do tipo PWR fabricada com tecnologia Westinghouse [6].

As ligas de níquel 82 e 182 são utilizadas como metais de adição em soldas dissimilares entre aços inoxidáveis e aços baixa liga por apresentarem coeficiente de expansão térmica intermediário aos dos metais de base, por diminuir o gradiente de difusão do carbono do aço baixa liga para o metal de adição e por sua elevada resistência à corrosão. Estas ligas também foram selecionadas por apresentarem coeficiente de condutividade térmica menor que os dos metais base, retendo localmente o calor resultante da operação de soldagem por mais tempo, necessitando-se assim de uma menor quantidade de calor durante o processo de soldagem (heat input) $[\mathbf{7}, \mathbf{8}, \mathbf{9}]$.

As soldagens dissimilares realizadas nos bocais do pressurizador das usinas nucleares semelhantes a Angra 1, são geralmente executadas em três etapas (Figura 2). Na primeira é aplicada uma camada de amanteigamento, com a espessura típica da camada final variando entre $5 \mathrm{~mm}$ e $8 \mathrm{~mm}$, sobre o bocal em aço baixa liga (aço ASTM A-508 G3). Para isto, utiliza-se como metal de adição a liga de níquel 82 e o processo de soldagem ao arco manual GTAW (Gas Tungsten Arc Welding). A camada de amanteigamento é uma alternativa benéfica para promover a transição entre materiais com diferentes valores de coeficiente de expansão térmica e ponto de fusão e gerar uma barreira que irá dificultar a migração de elementos de liga indesejáveis, do metal base para o metal de solda $[9,10,11,12]$.

A segunda etapa consiste de um tratamento térmico para o alívio das tensões geradas pelo amanteigamento do aço baixa liga, seguido de usinagem da superfície amanteigada para obtenção do perfil do chanfro. A duração do tratamento térmico é determinada pela espessura do componente de aço baixa liga e pelo número de passes ou pela espessura da camada de amanteigamento. Usualmente, a temperatura de encharque do tratamento térmico é de $580^{\circ} \mathrm{C} \mathrm{a} 620^{\circ} \mathrm{C}$ seguida de resfriamento ao ar [10].

$\mathrm{Na}$ terceira etapa é realizada a união do aço amanteigado ao aço inoxidável AISI 316L utilizando-se o processo GTAW e metal de adição, liga 82, nos passes de raiz. O preenchimento da junta é feito com a liga 182 empregando-se o processo SMAW (Shielded Metal Arc Welding). O tratamento térmico pós soldagem final poderá ou não ser realizado.

Em todas as etapas é recomendada a utilização do préaquecimento devido aos materiais apresentarem grandes espessuras, grande diferença no valor de coeficiente de expansão térmica e ao aço baixa liga apresentar elevado teor de carbono equivalente. O pré-aquecimento promove a redução da velocidade de resfriamento, que diminui a probabilidade de formação de martensita na zona afetada pelo calor (ZAC) do aço baixa liga e do trincamento a quente dos materiais envolvidos, além de uma diluição mais uniforme na poça de difusão e a consequente redução da necessidade de um elevado aporte térmico $[9,12,13]$.

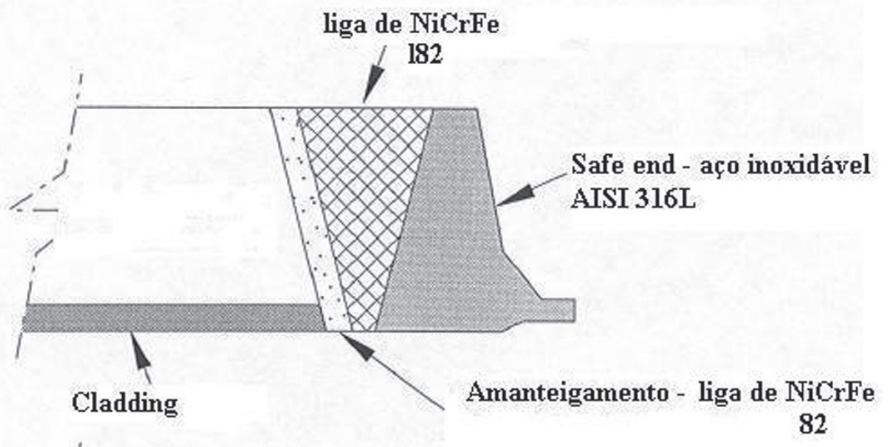

Figura 2 - Diagrama esquemático de uma solda dissimilar utilizada no pressurizador de Angra 1 [10].

As análises metalográficas dos metais de solda das ligas de níquel 82 e 182 mostram que as microestruturas consistem de grãos colunares de austenita separados em colônias de dendritas com orientações similares. Os contornos de grãos usualmente possuem a forma ondulada com aparência típica de uma estrutura soldada ou fundida. As dendritas formam-se paralelamente à direção do fluxo de calor durante a solidificação.

Na liga de níquel 82 inclusões de nitretos de titânio (TiN) e óxidos ricos em aluminío $(\mathrm{Al})$,manganês $(\mathrm{Mn})$ e silício $(\mathrm{Si})$ tendem a se formar nas regiões intergranulares. Inclusões de carbonetos e carbonitretos de nióbio e titânio também são observadas ao longo do contorno de grão. Os precipitados predominantes na liga de níquel 182 são carbonetos do tipo $\mathrm{M}_{23} \mathrm{C}_{6}$ e carbonetos à base de nióbio $(\mathrm{Nb})$ e titânio (Ti). A distribuição destes carbonetos não é contínua nos contornos de grão. As inclusões presentes são em sua maioria óxidos de Ti e TiN que coincidem com as regiões com maior conteúdo de manganês $[14,15]$. 
Tabela 1 - Composição química dos materiais base e de adição (\% em peso).

\begin{tabular}{|c|c|c|c|c|c|c|c|c|c|c|c|c|c|}
\hline & $\mathrm{C}$ & $\mathrm{Mn}$ & $\mathrm{Si}$ & $\mathrm{P}$ & $\mathrm{S}$ & $\mathrm{Cr}$ & $\mathrm{Ni}$ & $\mathrm{Nb}$ & $\mathrm{Ti}$ & $\mathrm{Cu}$ & $\mathrm{Mo}$ & $\mathrm{Al}$ & $\mathrm{Fe}$ \\
\hline 316L & 0,0230 & 1,458 & 0,4750 & 0,0210 & 0,0030 & 16,732 & 9,834 & 0,0199 & 0,0290 & 0,1420 & 2,0970 & 0,0110 & $\mathrm{Bal}$ \\
\hline $\mathrm{A} \mathrm{508}$ & 0,2130 & 1,336 & 0,2270 & 0,0050 & 0,0030 & 0,089 & 0,682 & 0,002 & 0,0010 & 0,0559 & 0,5050 & 0,0110 & $\mathrm{Bal}$ \\
\hline $182 *$ & 0,0470 & 5,810 & 0,5720 & 0,0150 & 0,0060 & 14,930 & 71,820 & 1,890 & 0,1830 & 0,0190 & - & - & $\mathrm{Bal}$ \\
\hline $82 *$ & 0,0400 & 2,810 & 0,0900 & 0,0030 & 0,0010 & 17,600 & 73,100 & 2,440 & 0,3500 & 0,0100 & - & - & $\mathrm{Bal}$ \\
\hline $182 * *$ & 0,0475 & 6,160 & 0,3410 & 0,0103 & 0,0099 & 14,330 & 70,300 & 2,070 & 0,0499 & 0,0118 & 0,2390 & 0,0108 & $\mathrm{Bal}$ \\
\hline $82 * *$ & 0,0433 & 3,400 & 0,1410 & 0,0012 & 0,0053 & 18,890 & 73,000 & 2,470 & 0,2520 & 0,0086 & 0,1550 & 0,0822 & $\mathrm{Bal}$ \\
\hline
\end{tabular}

*- análise eletrodo (fornecida pelo fabricante).

O trincamento por corrosão sob tensão (CST) em ambiente do circuito primário de uma usina nuclear PWR ocorre, principalmente, nas ligas de níquel das soldas dissimilares. Desta forma, o conhecimento da microestrutura destas ligas é um fator fundamental para avaliação deste processo. Alguns dos fatores microestruturais que afetam o comportamento frente à CST são a distribuição de carbonetos, precipitação ou segregação de impurezas nos contornos de grão e as condições de solidificação das microestruturas causadas pela operação de soldagem [16-21].

Este trabalho consistiu na soldagem de uma junta dissimilar de aço baixa liga ASTM A-508 G3 e aço inoxidável austenítico AISI 316L utilizando-se as ligas de níquel 82 e 182 como metais de adição e na posterior caracterização microestrutural das diversas regiões da junta soldada. A soldagem dos corpos de prova foi realizada manualmente empregando-se os processos GTAW e SMAW. São apresentadas as macro e microestruturas obtidas através de microscopia ótica, microscopia eletrônica de varredura (MEV), análise química por meio de energia dispersiva de raios X (EDS) e ensaios de microdureza Vickers.

\section{Materiais e Métodos}

\subsection{Materiais e Procedimento de Soldagem}

Para a realização da soldagem com materiais dissimilares utilizaram-se como metal base barras forjadas de aço do tipo ASTM A-508 G3 com dimensões de 36 mm de espessura, 230 $\mathrm{mm}$ de largura e $300 \mathrm{~mm}$ de comprimento, e barras de aço inoxidável austenítico AISI 316L com dimensões de $30 \mathrm{~mm}$ de espessura, $230 \mathrm{~mm}$ de largura e $300 \mathrm{~mm}$ de comprimento. Como metais de adição foram empregados o eletrodo revestido AWS A5.11 ENiCrFe-3 (liga de níquel 182) e o arame AWS A5.14 ENiCr-3 (liga de níquel 82), com diâmetros de 4 mm e 2,4 mm, respectivamente. A Tabela 1 mostra a caracterização química dos materiais realizada por meio da técnica de espectrometria de absorção atômica.

A soldagem do aço ASTM A-508 G3 ao aço inoxidável AISI 316L foi realizada manualmente, de acordo com especificações que reproduziram as condições reais da solda dissimilar de um bocal do pressurizador do reator nuclear de Angra 1 [22]. As barras foram pré-aquecidas a $150{ }^{\circ} \mathrm{C}$ antes da soldagem e a temperatura máxima entre passes foi de $200^{\circ} \mathrm{C}$. Na chapa de aço ASTM A-508, pré-aquecida, foi aplicada uma camada de "amanteigamento" (buttering) com espessura entre 5- $8 \mathrm{~mm}$ utilizando a liga de níquel 82 como metal de adição e o processo de soldagem ao arco manual com proteção gasosa GTAW (Gas Tungsten Arc Welding) (Figura 3). O gás de proteção empregado foi o Argônio (Ar) com vazão de 20 1/min. Após o amanteigamento a peça foi usinada e tratada termicamente a uma temperatura de $620^{\circ}$ por 2 horas com resfriamento ao forno, para alívio de tensão residual. Após a operação de usinagem avaliou-se a presença de descontinuidades na superfície pelo ensaio não destrutivo de líquido penetrante e não foi observado nenhum defeito.

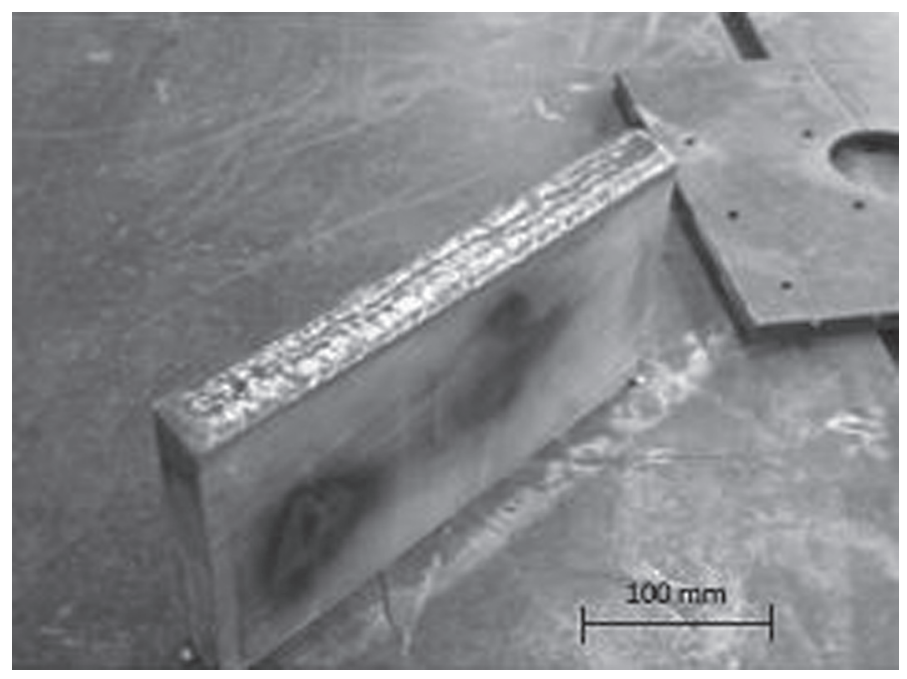

Figura 3 - Camada de "amanteigamento" aplicada no aço do tipo ASTM A-508 G3.

A união da chapa ASTM A-508 G3 “amanteigada" à chapa de aço AISI 316L foi realizada por meio do processo GTAW com vareta da liga de níquel 82 para o passe de raiz. Para o preenchimento do restante do chanfro utilizou-se a liga de níquel 182 como metal de adição e o processo de soldagem ao arco manual com eletrodo revestido SMAW (Shielded Metal Arc Welding). Após a soldagem, a peça teste não foi tratada termicamente, sendo submetida aos ensaios não destrutivos de líquido penetrante e radiografia e nenhum defeito foi revelado. Na Figura 4 é apresentada a configuração da junta soldada e na Tabela 2 são descritos os parâmetros de soldagem.

\subsection{Análise Metalográfica e Microdureza}

Após as operações de soldagem, a peça foi cortada para ensaios de microdureza e análise microestrutural. As amostras foram embutidas, lixadas e polidas até $1 \mu \mathrm{m}$ e foram atacadas 
Tabela 2 - Parâmetros de Soldagem.

\begin{tabular}{|c|c|c|c|c|c|c|}
\hline Cordãos & Processo & Metal de Adição & $\phi$ do eletrodo (mm) & Corrente(A) & Tensão (V) & $\begin{array}{c}\text { Velocidade de } \\
\text { Soldagem (mm/s) }\end{array}$ \\
\hline Amanteigamento & GTAW & 82 & 2,5 & $90-130$ & $17,5-18$ & $1,8-3,0$ \\
\hline Passe de raiz & GTAW & 82 & 2,5 & $126-168$ & $20-22$ & $1-1,2$ \\
\hline Junta soldada & SMAW & 182 & 4 & $119-135$ & $22-26$ & $1-3,5$ \\
\hline
\end{tabular}

para a análise micrográfica com reagentes e tempos de ataque compatíveis para identificação da microestrutura e revelação de contornos de grãos conforme mostrado na Tabela 3. As condições utilizadas nos ataques metalográficos foram baseadas no Metals Handbook [23] e otimizadas em testes de laboratório. As amostras foram observadas, fotografadas e analisadas por meio de microscopia ótica (MO), microscopia eletrônica de varredura (MEV) e microanálise por EDS (Energy Depressive Spectroscopy).

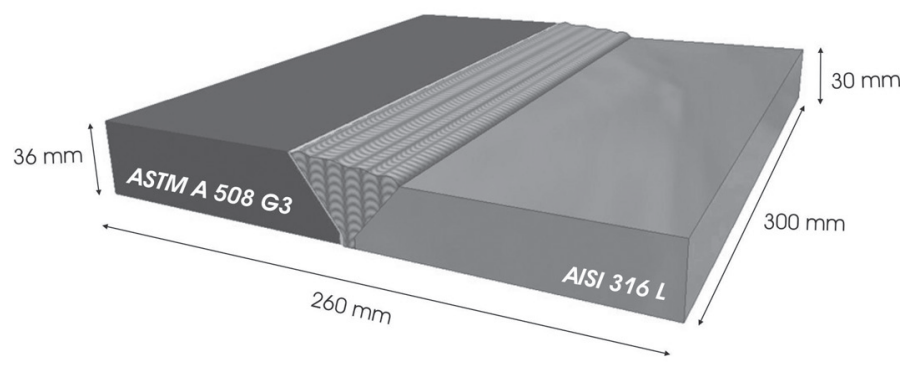

Figura 4- Representação esquemática da solda.

Tabela 3 - Condições de ataque metalográfico para revelar contornos de grão e precipitação de carbonetos.

\begin{tabular}{|l|l|}
\hline \multicolumn{1}{|c|}{ Amostra } & \multicolumn{1}{c|}{ Condições de Ataque } \\
\hline Aço ASTM A-508 G3 & $\begin{array}{l}\text { Nital 2\% - 20 segundos } \\
\text { (Imersão) }\end{array}$ \\
\hline Amanteigamento - Liga 82 & $\begin{array}{l}\text { Nital 2\% - 20 segundos } \\
\text { (Imersão) }\end{array}$ \\
\hline Aço Inoxidável - AISI 316L L & $\begin{array}{l}\text { Ácido fluorídrico 10\% -1A, } \\
\text { 2V, 60 segundos (Ataque } \\
\text { Eletrolítico) }\end{array}$ \\
\hline \multirow{2}{*}{ Cordão de Solda - Liga 182 } & $\begin{array}{l}\text { Ácido oxálico 10\% - 1A, } \\
\text { 2V, 30 segundos (Ataque } \\
\text { Eletrolítico) }\end{array}$ \\
\hline
\end{tabular}

Para a avaliação da microdureza Vickers, ao longo da junta dissimilar, foram feitas medições a partir dos metais base em direção ao metal de solda (perfis 1,3 e 5), da raiz à crista da solda (perfil 2) e ao longo do amanteigamento (perfil 4), conforme Figura 5. Utilizou-se uma carga constante de $100 \mathrm{~g}$ e um tempo de carregamento de 15 segundos.

A macrografia da seção transversal da junta soldada dissimilar é apresentada na Figura 6, onde se pode observar as diferentes regiões: amanteigamento (liga 82), solda (liga 182) e os metais de base ASTM A-508 G3 e AISI 316L. Observa-se a orientação das dendritas evidenciando a direção de resfriamento máximo durante a soldagem.

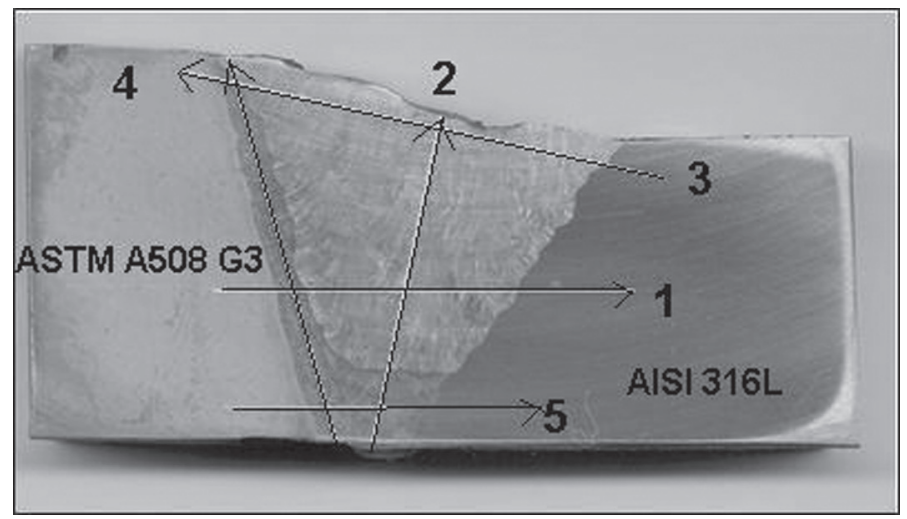

Figura 5 - Localização dos perfis de microdureza.

\section{Resultados e Discussão}

No nível macroestrutural, como cada cordão de solda se solidifica de uma poça de fusão, os pacotes de dendritas, nos quais as dendritas têm a mesma similaridade na orientação cristalográfica, crescem sempre na direção oposta ao fluxo de calor. Como cada cordão é depositado no mesmo sentido, a orientação cristalográfica das dendritas tende a se manter inalterada entre os diversos cordões [24]. Esta estrutura dendrítica colunar formada tende a ser perpendicular à raiz e à crista da solda no centro do cordão e apresenta ligeira curvatura em suas laterais, conforme mostrado na Figura 6.

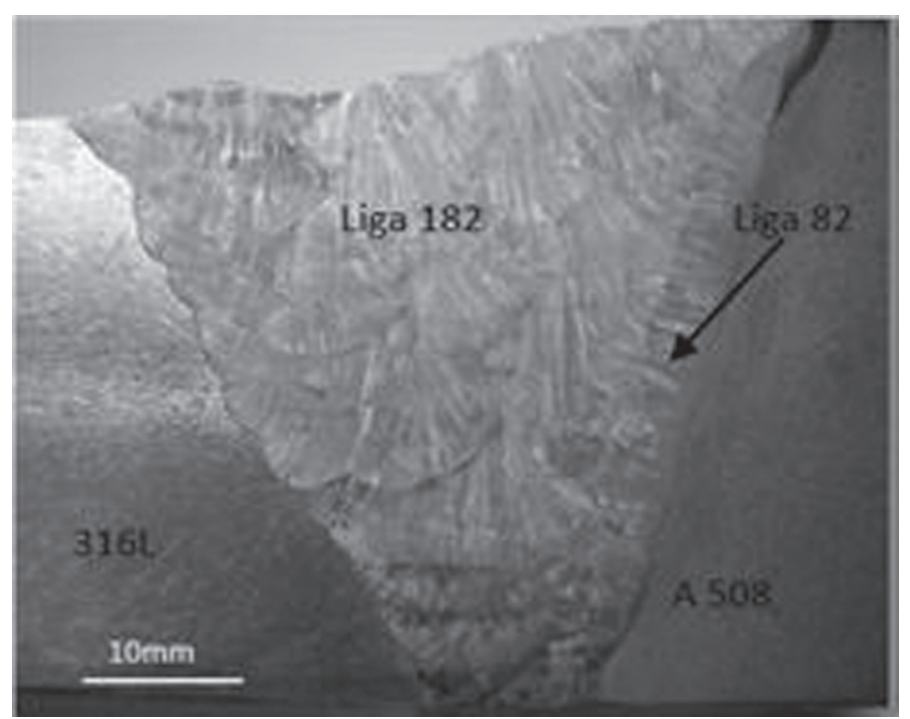

Figura 6 - Macrografia da junta soldada. 


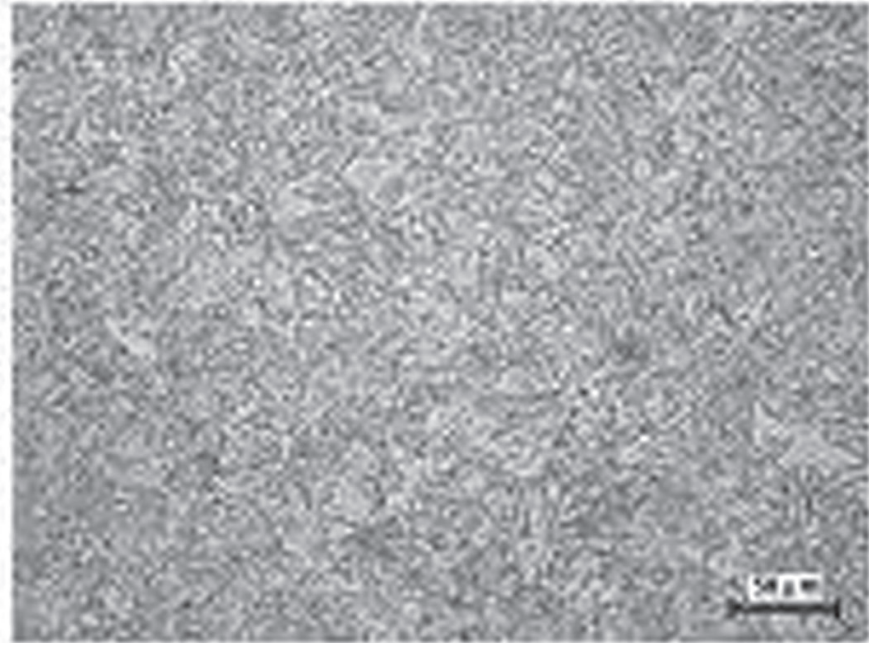

(a)

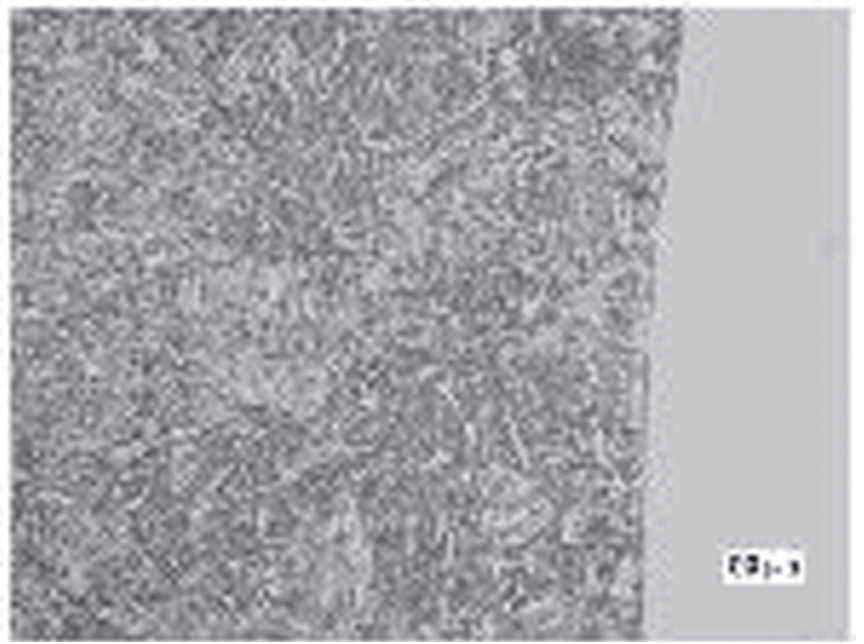

(b)

Figura 7 - Micrografia do Aço ASTM A-508 G3 (a) Região afastada da solda e (b) ZAC.

A microestrutura do aço ASTM A-508 G3 em uma região afastada da solda consiste em uma combinação de grãos de bainita e ferrita com finos carbonetos dispersos, característicos deste material no estado temperado e revenido (Figura 7 (a)). A Figura 7 (b) apresenta a micrografia da ZAC (Zona Afetada pelo Calor) na interface entre o aço baixa liga e o amanteigamento com a liga de níquel 82. A microestrutura é composta de região recristalizada de martensita revenida e grãos de ferrita.

Na Figura 8 é apresentada a micrografia do aço inoxidável austenítico 316L, em região afastada da solda. A microestrutura consiste de grãos poligonais de austenita e da presença de pequena quantidade de ferrita delta (fase escura alongada).

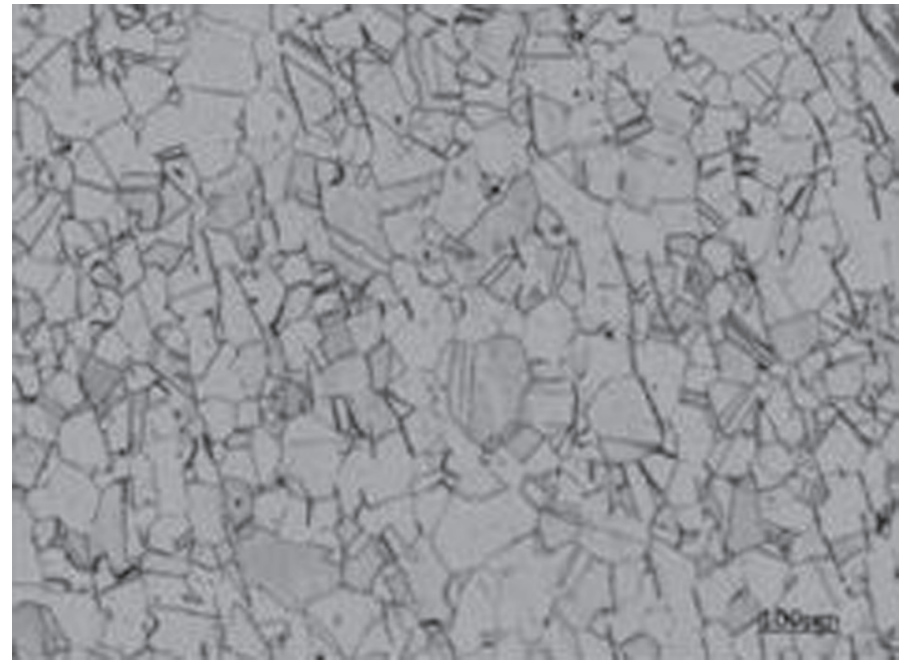

Figura 8 - Microestruturas típicas do metal base AISI 316L em região afastada da solda.

As microestruturas das diversas regiões da junta soldada dissimilar (passe de raiz, zona fundida central e amanteigamento) são mostradas na Figura 9. Observam-se microestruturas completamente austeníticas na zona fundida central e na região do amanteigamento, às quais não sofreram transformações alotrópicas durante a operação de soldagem [25]. Nota-se na região do amanteigamento e na zona fundida central uma textura dendrítica com precipitados intra e interdendriticos. A estrutura do grão é anisotrópica, à medida que se formam colunares na direção do fluxo de calor, aproximadamente normais à direção de soldagem. Esta microestrutura é consistente com os estudos realizados por Sireesha et.al e Peng et. al $[26,27]$.

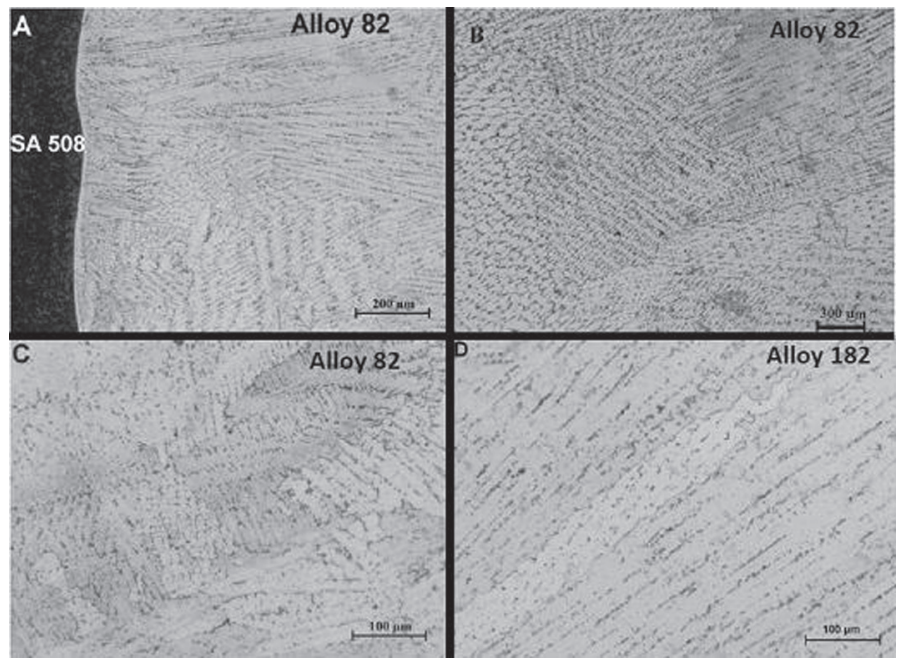

Figura 9 - Microestruturas da junta (a) ASTM A-508 G3/ Liga 82, (b) Região do Amanteigamento - Liga 82, (c) Passe de Raiz - Liga 82 e (d) Região da Zona Fundida Central - Liga 182.

Os contornos de grãos formados entre os pacotes de dendritas, que têm diferentes orientações cristalográficas, são ondulados e não retilíneos em contraste com os contornos de grãos poligonais nos casos de materiais forjados e laminados, como mostrado na Figura 8. O contorno de grão é definido como a linha entre os pacotes de dendritas cujas orientações cristalográficas são superiores a $15^{\circ}$. Este é o local preferencial no caso de trincamento por corrosão sob tensão das ligas 182, sendo geralmente de natureza intergranular [24]. A estrutura bruta (bruta de solidificação) apresenta uma desorientação entre os grãos bastante acentuada e isto tende a ser benéfico, pois 
dificulta a propagação de trincas.

Na Figura 10 é mostrada uma região da linha de fusão entre o metal de adição da liga 182 e o aço inoxidável AISI 316L. Observa-se nesta interface a presença de uma zona parcialmente fundida, constituída de austenita e dendritas de ferrita delta. Soldas dissimilares são conhecidas por exibir uma zona parcialmente fundida onde a microestrutura e a composição química são diferentes daquelas do metal base adjacente à zona fundida [19]. Esta zona tende a formar-se perto da interface do metal base que possui maior ponto de fusão (aço inoxidável AISI 316L), sendo que as correntes de convecção não são suficientes para promover um fluxo adequado de fluido e a homogeneização da poça fundida [17].

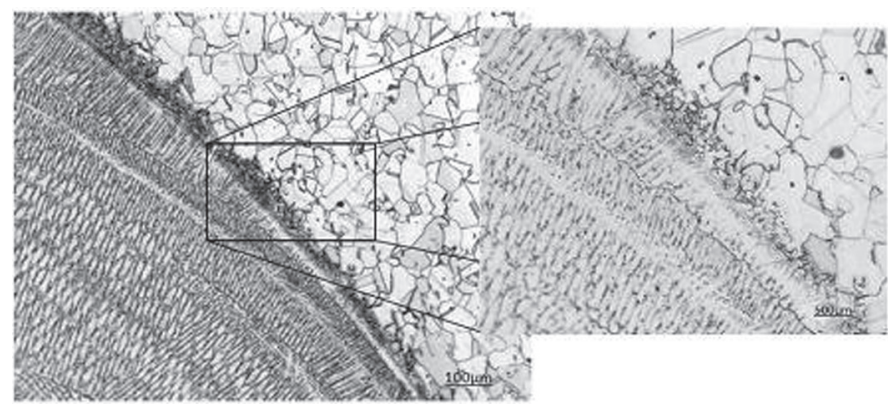

Figura 10 - Microestrutura da linha de fusão entre o metal de solda da liga 182 e aço inoxidável austenítico AISI 316L.

Na Figura 11 são mostradas as microanálises feitas por EDS na região do metal de adição da liga 182. Observa-se a presença dos principais elementos de liga - cromo $(\mathrm{Cr})$, níquel (Ni) e ferro $(\mathrm{Fe})$ e também dos elementos carbono $(\mathrm{C})$, silício (Si), manganês (Mn), titânio (Ti), nióbio ( $\mathrm{Nb}$ ) e alumínio (Al). Estes picos sugerem a presença de precipitados do tipo carbonetos de nióbio, titânio, cromo e segregações de alumínio, silício e manganês, semelhante às microanálises obtidas no trabalho realizados por Cieleska e Peng et al [28,29]. Não foram observadas segregações de impurezas como fósforo e enxofre nos contornos de grão.

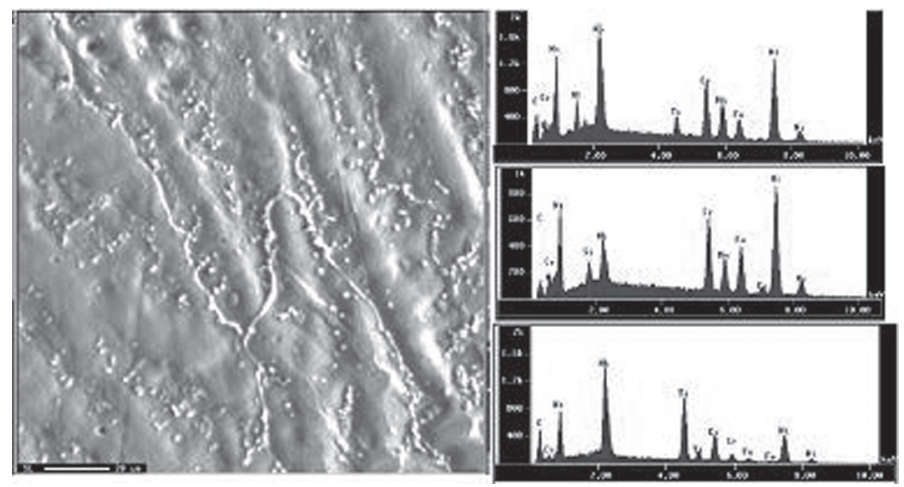

Figura 11 - Espectro feito por EDS dos precipitados encontrados no metal de solda - liga 182.

Na Figura 12 é mostrado o mapeamento por EDS realizado no metal de solda da liga 182. Ficou evidenciado a presença de carbono, cromo, silício, titânio, manganês, ferro, níquel e nióbio. Carbono, nióbio e titânio se apresentam na forma de carbonetos/carbonitretos precipitados na matriz e nos contornos de grão. O manganês está presente como sulfeto de manganês, segregado durante o processo de soldagem por possuir um ponto de fusão menor e está localizado, preferencialmente, na região interdendrítica. $\mathrm{O}$ silício esta distribuído uniformemente na matriz.

O perfil da composição química, realizado por EDS, a partir do aço ASTM A-508 G3 em direção a zona fundida da liga 182, é mostrado na Figura 13. Pode-se observar que onde há uma variação da composição dos elementos níquel e cromo também ocorre uma variação nas concentrações de nióbio, silício e titânio nas regiões dos metais de solda das ligas 82 e 182. Há uma pequena redução no conteúdo de cromo quando se muda da liga 82 para a 182 devido à diferença do conteúdo deste elemento entre as ligas A diminuição do teor do elemento ferro na direção do metal de solda indica a zona de diluição. Ainda na análise por EDS foi percebida uma variação do teor de cromo intragranular ou intradendrítico. A Figura 14 evidencia esta situação.

Na Figura 15 são apresentados os perfis de microdureza Vickers (HV), com carga de 100 gramas. Nesta figura, os perfis 1,3 e 5 mostram a distribuição ao longo da solda dissimilar. Os resultados mostram que os valores de microdureza Vickers obtidos na ZAC do aço ASTM A-508 G3 foram muito próximos aos obtidos para os metais de solda das ligas 82 e 182 . Estes resultados demonstram que o tratamento térmico aplicado após a operação de amanteigamento foi apropriado para reduzir a formação da estrutura martensítica e, consequentemente, para a diminuição da tensão residual presente nesta região. Estes perfis, junto com os perfis 2 e 4 do metal de solda da liga 182 e do amanteigamento, liga 82, mostram valores de microdureza variando entre 180 e $270 \mathrm{HV}$.
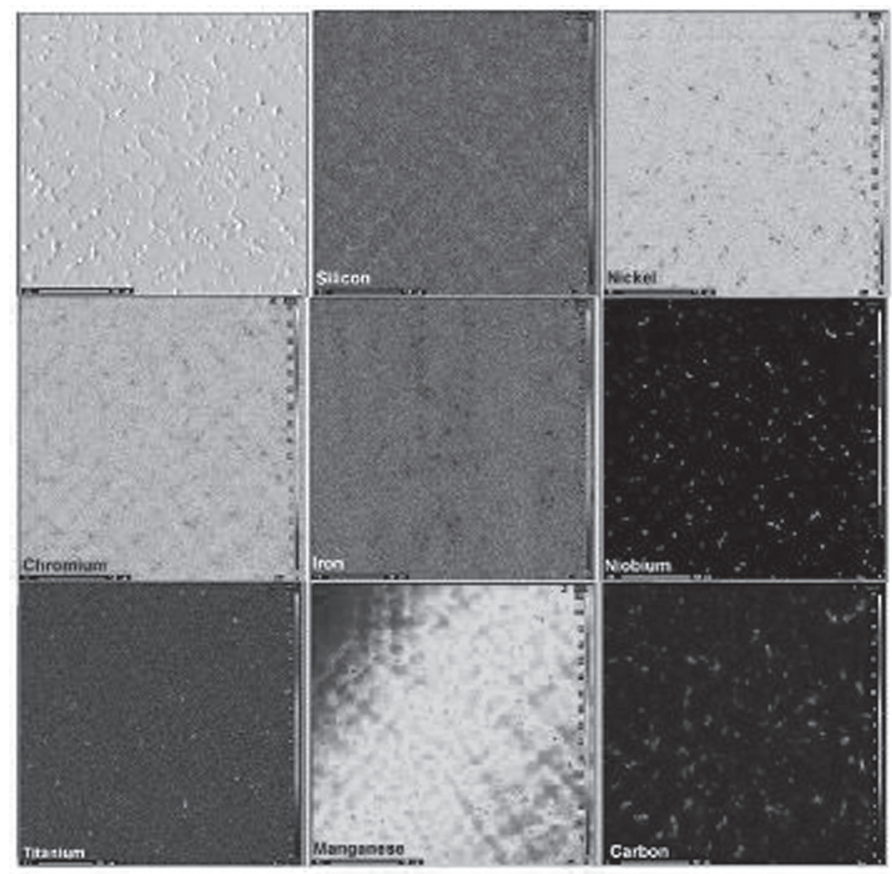

Figura 12 - Distribuição dos elementos Si, Ni, Cr, Fe, Nb, C, Ti e Mn no metal de solda da liga 182. 


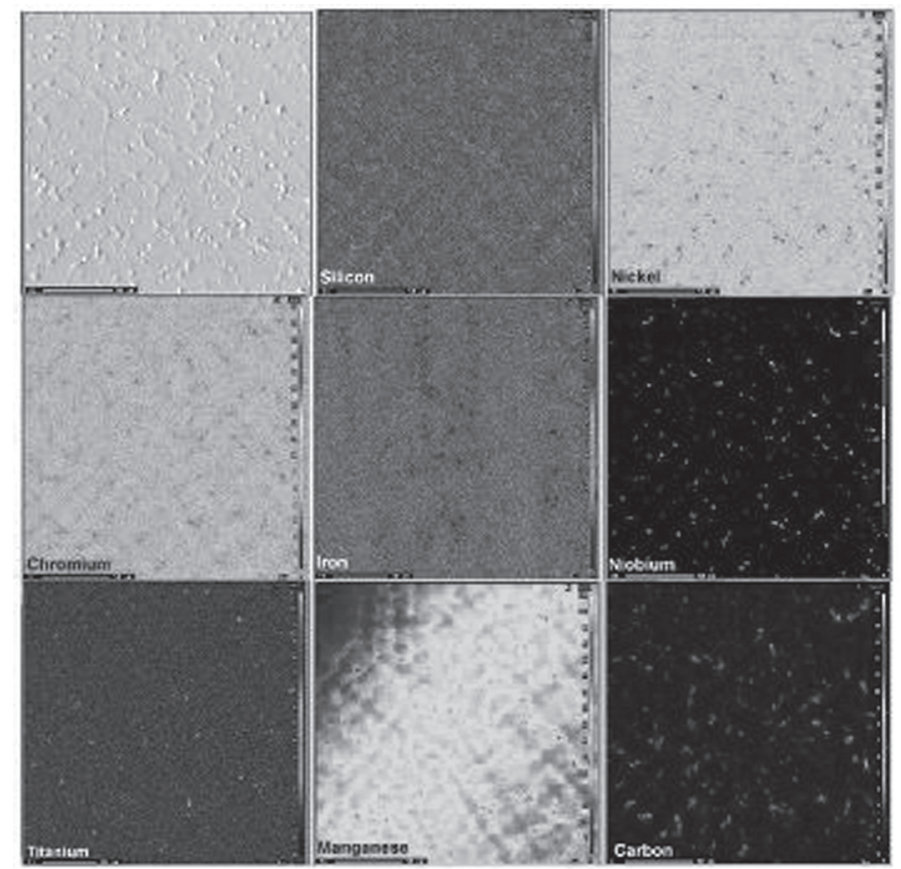

Figura 13 - Perfil da composição dos elementos Mn, Ti, Ni, Cr, $\mathrm{Si}, \mathrm{Nb}$ e Fe feito no metal base ASTM A-508 G3 em direção a zona fundida da liga 182.
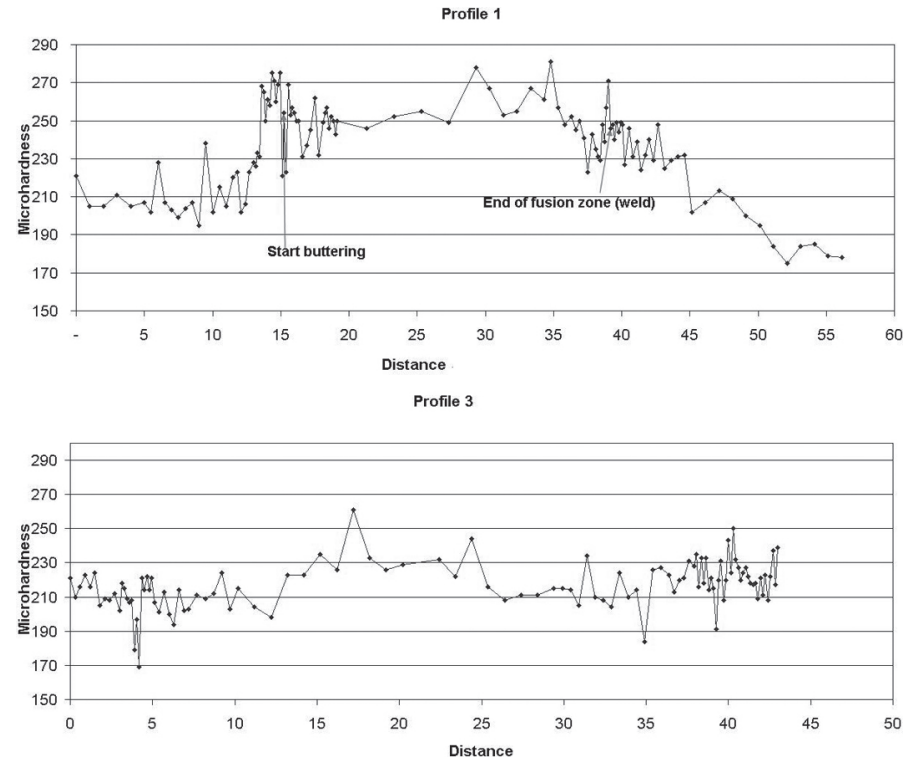

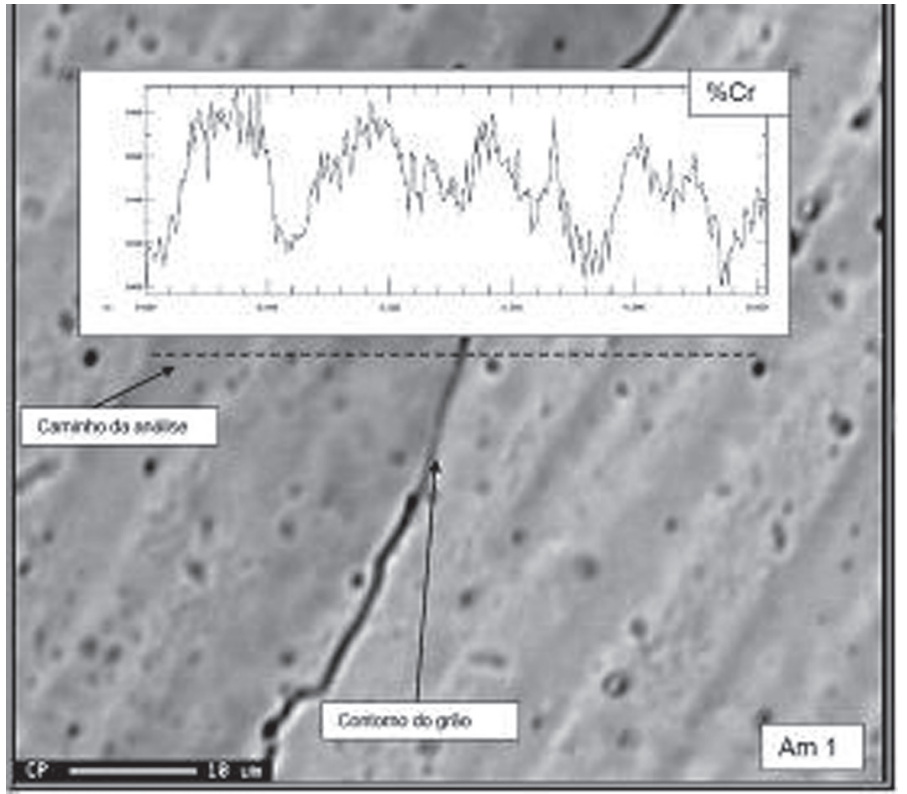

Figura 14 - Microfotografia obtida no MEV e análise por EDS mostrando a variação intradendritica do teor de cromo na liga 182.
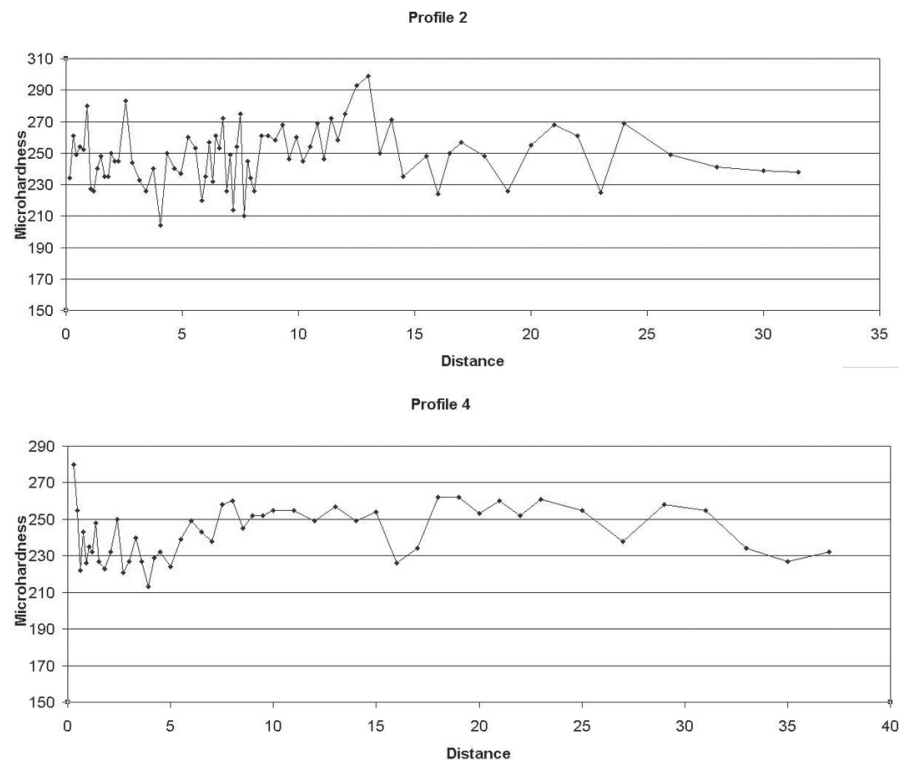

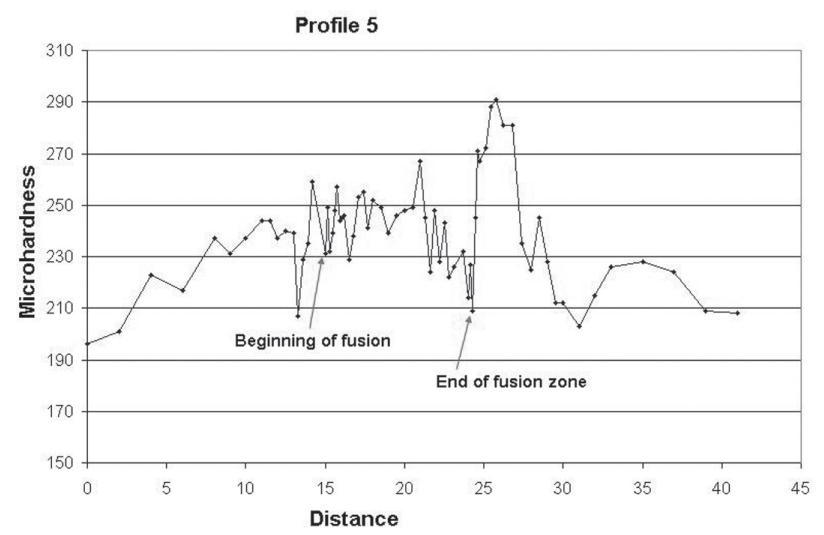

Figura 15 - Perfis de microdureza da junta dissimilar. 


\section{Conclusões}

A partir dos resultados obtidos, pode-se concluir que:

1) A microestrutura predominante na região soldada é constituída de dendritas de austenita e precipitados intra e interdendriticos.

2) No metal de solda foi observada a precipitação de carbonetos de nióbio, titânio e cromo e segregações de alumínio, silício e manganês. Não foi verificada a segregação dos elementos fósforo, e silício.

3) A dureza ao longo da junta dissimilar não apresentou variações muito significativas, sendo que a região da zona fundida apresentou valores de microdureza ligeiramente maiores do que ambos os metais base.

\section{Agradecimentos}

Os autores agradecem à Fundação de Amparo à Pesquisa do Estado de Minas Gerais - FAPEMIG, à Financiadora de Estudos e Projetos - FINEP, à Eletronuclear- Eletrobrás Termonuclear S.A e ao Centro de Desenvolvimento da Tecnologia Nuclear CDTN/CNEN pelo apoio financeiro. Agradecem, também, aos técnicos Antônio Edicleto Gomes Soares, Antônio Eugênio de Aguiar e Geraldo Antônio Scoralick Martins pelo apoio à pesquisa.

\section{Referências Bibliográficas}

[1] JANG, C., LEE. J., KIM, S. J., JIN, E. T. Mechanical Property Variation Within Inconel 82/182 Dissimilar Metal Weld Between Low Alloy Steel and 316 Stainless Steel. International Journal of Pressure Vessels and Piping, 2007, N. 9, p. 635-646.

[2] Global Energy Systems and Common Analyses - Final Report of Annex X (2005-2008). ETSAP - International Energy Agency Implementing Agreement for a Programme of Energy Technology Systems Analysis. Ed. Gary Goldstein and GianCarlo Tosato, June, 2008.

[3] USNRC Technical Training Center - United States Regulatory Commission. Reactor Concepts Manual. Pressurized water Reactor Systems. Disponível em: http://www.nrc.gov/readingrm/basic-ref/teachers/04.pdf.

[4] IAEA - International Atomic Energy Agency. Assesment and Management of Ageing of Major Nuclear Power Plant Components Important to Safety - Primary Piping in PWRs. IAEA - TECDOC 1361, 2003.

[5] IAEA - International Atomic Energy Agency. Assessment and Management of Ageing of Major Nuclear Power Plant Components Important to Safety - Steam Generators. IAEA TECDOC 981, 1997.

[6] EPRI - Electric Power Research Institute. Primary System Piping Butt Weld Inspection and Evaluation Guidelines.

Materials Reliability Program - MRP 139, 2005.

[7]TILLACK, D.J. Selection of Nickel, Nickel-Copper, NickelChromium-Iron Alloys. In: ASM - American Society for Metals,
Metals Handbook, Welding, Brazing and Soldering, 1993, v.6, p. 1456 ,.

[8] KIM, J.W., LEE, K., KIM, J.S., BYUN, T.S. Local Mechanical Properties of Alloy 82/182 Dissimilar Weld Joint Between SA 508 Gr.1 and F316 SS at RT and $320^{\circ} \mathrm{C}$. Journal of Nuclear Materials, 2009, N. 384, p. 212-221.

[9] SCHAEFER, A., Dissimilar Metal Weld Failure Problems in Large Steam Generators. Power, 1979, N. 12, p.68-69.

[10] MITEV, R., TAYLOR, N. G. General review of dissimilar metal welds in piping systems of pressurized water reactors, including WWER designs. European Commission DG-JRC/IE, Petten, Netherlands, EUR 22469 EN, 2006.

[11] FAIDY, C., GILLES, P. Assessment of Dissimilar Weld Integrity: Final Report of the NESC-III project. European Comission, EUR 22510 EM, 2006.

[12] DAVIS, J.R. Corrosion of Dissimilar Metal Weldments. In: ASM - American Society for Metals, Corrosion of Weldments, 2006, cap 9, p. 170.

[13] FALLATAH, M.G., SHEIKH, K.A., KHAN, Z., BOAH, K.J. Reliability of Dissimilar Metal Welds subjected to Sulfide Stress Cracking. KFUPM - King Fahd University of Petroleum \& Minerals, 2002. The 6th Saudi Engineering Conference, Dhahran, Saudi Arabia, December, v. 5, p. 297-312.

[14] ALEXANDREANU, B., CHOPRA, K.O., SHACK, J. W. Crack Growth Rates and Metallographic Examinations of Alloy 600 and Alloys 82/182 from Field Components and Laboratory Materials Tested in PWR Environments. Argone National Laboratory - NUREG/CR-6964. US. Nuclear Regulatory Commission Office of Nuclear Regulatory Research, Maio, 2008.

[15] EPRI - Electric Power Research Institute. Crack Growth Rates for Evaluating Primary Water Stress Corrosion Cracking (PWSCC) of Alloy 82, 182, and 132. Materials Reliability Program - MRP 115, 2004.

[16] SCOTT, P.M. An Overview of Materials Degradation by Stress Corrosion in PWRs. Eurocorr- Annual European Corrosion Conference of the European Federation of Corrosion, Nice, Acropolis, 12 - 16 de Setembro, 2004.

[17] ALEXANDREANU, B., CHEN, Y., CHOPRA, K.O., CHUNG, M.H., GRUBER, E.E., SOPPET, K.W., SHACK, J. W. Environmentally Assisted Cracking in Light Water Reactors. Argone National Laboratory - NUREG/CR-4667. US. Nuclear Regulatory Commission Office of Nuclear Regulatory Research, Março, 2007.

[18] GOMEZ-BRICEÑO, D., SERRANO, M. Aleaciones Base Niquel em Condiciones de Primario de Los Reactores Tipo PWR. Materiales, Março, 2005.

[19] BAMFORD, W., HALL, J. A Review of Alloy 600 Cracking in Operating Nuclear Plants: Historical Experience and Future Trends. TMS (The Minerals, Metals \& Materials Society), 2003. 11 th Internation Conference Environmental Degradation of Materials in Nuclear Systems, Stevenson, WA, 10-14 de Agosto, 2003.

[20] THOMAS, L., JOHNSON, B.R., VETRANO, J.S., BRUEMMER, S.M. Microestructural and Microchemistry 
Characterization of Primary-Side Cracks in an Alloy 600 Nozzle Head Penetration and its Alloy 182 J-Weld from the DavisBesse Reactor Vessel. TMS (The Minerals, Metals \& Materials Society), 2005. Proceedings of the 12th International Conference on Environmental Degradation of Materials in Nuclear Power System - Water Reactors,

[21] CHOPRA, K.O., SOPPET, K.W., SHACK, J. W. Effects of Alloy Chemistry, Cold Work and Water Chemistry on Corrosion Fatigue and Stress Corrosion Cracking of Nickel Alloys and Welds. Argone National Laboratory - NUREG/CR-6721. US. Nuclear Regulatory Commission Office of Nuclear Regulatory Research, Março, 2001.

[22] ASME - American Society of Mechanical Engineers Boiler and Pressure Vessel Code - Section IX, Welding and Brazing Qualification, 2004.

[23] ASM - American Society for Metals - Metals Handbook $8^{\circ}$ ed - In: Metallographic Technique for Specific Metals and Alloys, v. 8, p.101, 1973.

[24] EPRI - Electric Power Research Institute. Review of SCC of Alloys 182, 82 in PWR Primary Service. Materials Reliability Program - MRP 220, 2007. Disponível em: www.epriweb.com/ public/000000000001015427.pdf

[25] DEHMOLEI, R., SHAMANIAN, M., KERMANPUR, A. Microstructural Characterization of Dissimilar Welds Between Alloy 800 and HP Heat-Resistant Alloys. Materials Characterization, 2008, N. 59, p. 1447-1454.

[26] SIREESHA, M., SHANKAR, V., ALBERT, SHAJU K., SUNDARESAN, S. Microstructural features of dissimilar welds between 316LN austenitic stainless steel and alloy 800 . Materials Science and Engineering, 2000, N. 292, p. 74-82.

[27] PENG, Q. J. , SHOJI, T., YAMAUCHI, H., TAKEDA, Y. Intergranular Environmentally Assisted Cracking of Alloy 182 Weld Metal in Simulated Normal Water Chemistry of Boiling Water Reactor. Corrosion Science, 2007 N. 49, p. 2767-2780.

[28] CIELESKA, M. J. The Welding and Solidification Metallurgy of Alloy 625. Welding Journal, 1991, February, V 70, p. 49s-56s.

[29] PENG, Q.J., YAMAUCHI, H., SHOJI, T. Investigation of Dendrite-Boundary Microchemistry in Alloy 182 using Auger electron spectroscopy Analysis. Metallurgical and Materials Transactions A, 2003, September, V 34A, p. 1891-1899. 